\title{
JONAS MEKAS - CINEMA EM LAMPEJOS
}

\author{
Bruna Machado Ferreira ${ }^{*}$ \\ Universidade Federal de Santa Catarina
}

Resumo: Este artigo apresenta reflexões acerca da criação cinematográfica de Jonas Mekas, um dos realizadores e pensadores do cinema de vanguarda norte-americano, que, como tal, traz, em seus filmes, a marca da reproposição da linguagem/montagem, uma outra compreensão do tempo e sua passagem, via o abandono da cronologia e de qualquer linearidade narrativa. A partir deste argumento, desdobra-se a leitura de um cinema que se faz no e pelo deslocamento, o trânsito pelo cotidiano, abertura para o acaso, contingência; que não parte de uma unidade espaço-temporal, mas se fragmenta - fragmento este que se apresenta como possibilidade ética diante da alteridade; passagens, rastros, vestígios de um gesto. Cenas que projetam o íntimo no público em uma espécie de celebração contínua e despretensiosa do cotidiano, do familiar. Cinema em exílio, cinema-asilo - ao mesmo tempo, sobrevivência e suspensão de uma memória, abrigo do corpo, da linguagem, do encontro, onde parece sempre se desenhar a possibilidade, abertura para a invenção de um espaço novo, inédito, espaço-vida, espaço-arte, sem fronteiras.

Palavras-chave: Cinema. Cotidiano. Fragmento. Trânsito. Asilo.

As I Was Moving Ahead Occasionally I Saw Brief Glimpses of Beauty (2000/2001) é um dos inúmeros filmes de Jonas Mekas - aos 92 anos de idade, sua produção continua intensa. Em um dos trechos (o filme tem aproximadamente cinco horas, destaco apenas dois minutos $^{1}$ ), enquanto vemos imagens ordinárias, cotidianas ${ }^{2}$ - que surgem após uma cartela com o nome do filme escrito à mão, e outra com chapter one datilografado, à máquina -, o próprio Jonas Mekas narra, em off:

I have never been able to figure out where my life begins and where it ends. I have never, never been able to figure it all out, what it's all about, what it all means. So

\section{Esta obra está licenciada sob uma Creative Commons - Atribuição 4.0}

\footnotetext{
* Possui graduação em Audiovisual pela Universidade de Brasília (2009). Tem experiência na área de Comunicação, com ênfase em CINEMA, TELEVISÃO E RÁDIO, atuando principalmente nos seguintes temas: docudrama, tropicália e rádio. Mestra em Literatura pela Universidade Federal de Santa Catarina, Programa de Pós-Graduação em Literatura, Área de Concentração Literaturas. E-mail: brunamferreira@gmail.com

${ }^{1}$ Não tive acesso ao filme por inteiro, os trechos que destaco ao longo do texto estão disponíveis no sítio eletrônico youtube $<$ https://www.youtube.com/ $>$.

${ }^{2}$ Assim podemos a grosso modo enumerar essas imagens, apenas a título de situar, e não ordenar: as ruas de uma cidade; uma moça tocando violino; um gato brincando; um homem com seu cachorro; o próprio Jonas Mekas com um bebê; uma cartela que anuncia um batismo (Baptism de Una Abraham), seguida por seus supostos acontecimentos; outra que anuncia home scenes, seguida por uma mulher e um bebê que brincam com um gato sobre a mesa.
} 
when I began now to put all this rolls of film together, to string them together, the first idea was to keep them chronological. But then I gave up and I just began splicing them together by chance, the way I found them on the shelf. Because I really don't know where any piece of my life really belongs, so let it be, let it go, just by pure chance, disorder. There is some clearance [?], some kind of order in it, order of its own which I do not really understand, chain as I've never understood. Life around me, the real life as they say or the real people. I've never understood them, I still not understand them and I do not really want to understand them ${ }^{3}$.

Eduardo Coutinho, em um debate em torno de um seminário que se intitulava $O$ Sujeito (Extra)Ordinário, que abordava, dentre outras questões, (o que e/ou quais seriam, ou não) as fronteiras, limiares entre um suposto cinema documentário e um cinema de ficção, dentro da III Conferência Internacional de Documentário, realizada em 2003, com a temática Imagens da Subjetividade, assim se refere ao filme de Jonas Mekas:

Há um filme de um diretor do underground americano, Jonas Mekas, um filme testamento, de cinco horas. E é maravilhoso porque você pode sair e voltar, e nada acontece. E isso é extraordinário. São células de trinta minutos. Você acabou de ver Verão no Central Park e vai ao banheiro. Depois volta e Verão no Central Park ainda está lá. Adoro esse filme. Poucas vezes vi alguém tratar dessa questão da passagem do tempo de forma tão interessante. Particularmente, gosto porque é um filme no qual ninguém fala uma palavra. $\mathrm{O}$ nome do filme é enorme. É mais ou menos assim: Enquanto eu avançava, via ocasionalmente breves lampejos de beleza [As I Was Moving Ahead Occasionally I Saw Brief Glimpses of Beauty]. E eu soube desse filme que, mesmo em Nova York, lá nesse gueto extraordinário, depois de duas horas de projeção não há ninguém mais na sala. Vi uma cópia horrível em VHS, não havia cores, não havia nada, mas tive vontade de chorar. Há muito tempo não me emocionava por causa de um filme. Esse filme é um diário, que mostra Mekas, sua família e seus amigos. Não há nenhum grande acontecimento político ou social. E ele faz comentários em certos momentos. São pequenos títulos, capítulos de um minuto ou sete, e às vezes o título não tem nada a ver com o conteúdo. Há comentários falados em off pelo próprio Mekas. Há também uma música ao piano que acompanha, mas nenhum som direto (COUTINHO apud MOURÃO; LABAKI, 2005, p. 111-112).

$\mathrm{Na}$ fala de Coutinho encontramos, caracterizando o filme de Mekas, a marca da vanguarda e sua reproposição da linguagem, da montagem cinematográfica; uma outra compreensão do tempo e sua passagem, um abandono da cronologia e de qualquer linearidade narrativa - arriscamos dizer que Cronos, "o tempo da medida, que fixa as coisas e as pessoas, desenvolve uma forma e determina um sujeito", é substituído por Aion, "o tempo indefinido do acontecimento, a linha flutuante que só conhece velocidades, e ao mesmo tempo não pára

\footnotetext{
3 "Eu nunca fui capaz de compreender onde minha vida começa ou onde termina. Eu nunca fui capaz de compreender tudo, o que tudo isso significa. Logo, quando eu comecei a colocar todos esses rolos de filmes juntos, a encadeá-los, a primeira ideia foi mantê-los cronologicamente. Mas depois eu desisti e comecei a juntálos aleatoriamente, da forma como os encontrava na prateleira. Como eu realmente não sei onde qualquer pedaço da minha vida começa, então deixa estar, deixa ir, apenas por puro acaso, desordem. Há algum apuro, algum tipo de ordem nisso, ordem própria a qual eu realmente não entendo, ligados de uma forma que nunca entendi. A vida ao meu redor, a vida real como dizem, ou as pessoas reais. Eu nunca as entendi, eu ainda não as entendo e eu realmente não quero entendê-las" (Disponível em: $<$ https://www.youtube.com/watch?v=XhmZ7CoXDY\&list=PLwSrxwpZVGaEYu5goVDoI8XNFgyWOZs Y > . Acesso em: 15 agosto 2014. Tradução nossa).
}

Anu. Lit., Florianópolis, v. 20, n. 2, p. 55-66, 2015. ISSNe 2175-7917 
de dividir o que acontece num já-aí e um ainda-não-aí, um tarde-demais e um cedo-demais simultâneos, um algo que ao mesmo tempo vai se passar e acaba de se passar" (DELEUZE; GUATTARI, 1997, p. 48-49). Abertura para o acaso decorrente de uma vivência da arte via o deslocamento, o trânsito pelo cotidiano, o trânsito do cotidiano. Um cinema performático que não parte de uma unidade espaço-temporal, e se faz mesmo a partir de fragmentos fragmento este que se apresenta como possibilidade ética diante da alteridade; passagens, rastros, vestígios de um gesto.

"Pequenas histórias na grande história" (DIDI-HUBERMAN, 2011, p. 17). Em seu texto intitulado Anti-100 Years of Cinema Manifesto ("Manifesto Anti-100 Anos de Cinema"), Mekas, à maneira, em certa medida, da leitura que Didi-Huberman (2011) realiza das cartas de Pasolini - em que a imagem dos vaga-lumes como pequenas luzes, reminiscências e sobrevivências aparecem em contraposição aos grandes holofotes do poder fascista e da guerra -, assim coloca:

\begin{abstract}
In the time of bigness, spectaculars, one hundred million movie productions, I want to speak for the small, invisible acts of human spirit, so subtle so small that they die when brought out under the Kleegue lights.

I want to celebrate the small forms of cinema, the lyrical forms, the poem, the watercolor, etude, sketch, postcard, arabesque, triolet, and bagatelle, and little 8-mm songs.

In the times when everybody wants to succeed and sell, I want to celebrate those who embrace social and daily failure to pursue the invisible, the personal, things that bring no money and no bread and make no contemporary history - art history or any history $-^{4}$
\end{abstract}

Borramentos, apagamentos de fronteiras: nas cenas captadas da vida de Andy Warhol - e que aparecem também como uma negação do (auto)biográfico como uma narrativa grandiosa -, Mekas brinca com as cartelas/letreiros que antecedem determinadas imagens: "this is a documentary film"/“this not a documentary film" ("isto é um filme documentário/isto não é um filme documentário"). "Home movies", como costuma descrever o seu trabalho, ou "home scenes". Cenas, apenas cenas, que projetam o íntimo no público em uma espécie de celebração contínua e despretensiosa do cotidiano, do familiar; "um cerimoniar das atitudes mais 'correntes, mais vulgares, mais banais" (DELEUZE, 2005, p. 230) - eis o cinema de Jonas Mekas.

\footnotetext{
4 "Em tempos de grandeza, espetáculos, produções cinematográficas de cem milhões, eu quero falar dos pequenos, invisíveis atos do espírito humano, tão sutis, tão pequenos que morrem quando trazidos às luzes dos holofotes.// Eu quero celebrar as pequenas formas de cinema, as formas líricas, o poema, a aquarela, étude, esquete, cartão postal, arabesco, triolé, bagatelle, e pequenas canções $8 \mathrm{~mm} . / /$ Em tempos em que todo mundo quer fazer sucesso e vender, eu quero celebrar aqueles que abraçam o fracasso, social e diariamente, para buscar o invisível, o pessoal, coisas que não trazem dinheiro ou pão, e não fazem história contemporânea - história da arte ou qualquer outra história -" (MEKAS, Jonas. Anti-100 Years of Cinema Manifesto. Disponível em: $<$ http://jonasmekas.com/diary/?p=1658 $>$. Acesso em: 28 março 2015. Tradução nossa).
}

Anu. Lit., Florianópolis, v. 20, n. 2, p. 55-66, 2015. ISSNe 2175-7917 


\section{Cinema-corpo em trânsito}

O $16 \mathrm{~mm}$, como formato cinematográfico, foi desenvolvido e lançado no mercado pela Kodak no início da década de 1920, voltado, inicialmente, para o cinema amador, filmes domésticos (posteriormente, em meados de 1960, é o $8 \mathrm{~mm}$ - e o respectivo aperfeiçoamento desta bitola, o super-8 - que aparece para cumprir tais funções, sejam registros diários, eventos, viagens, vida familiar, etc). Entretanto, dada a possibilidade de uma câmera em trânsito, da ideia de um cinema a partir da mobilidade/leveza, o formato acabou por mediar a (des)estruturação, em termos estilísticos, de produções cinematográficas como - só para ficar em alguns exemplos - os documentários do cinema verdade, os filmes da Nouvelle Vague francesa, e do cinema novo brasileiro. Seu custo inferior ao formato então "oficial", o $35 \mathrm{~mm}$, popularizou-o como marca estética do que, por uma questão, ou melhor, necessidade de classificação do estranho, fora de padrão - ou o que no contexto de produção e proposições hollywoodianas não correspondia tanto à janela como à uma decupagem clássica, uma relação clara, óbvia entre a organização da linguagem do cinema e o discurso falado - veio a ser denominado como um experimentalismo, a intervenção técnica com implicação a nível de linguagem.

Um pouco depois de ter chegado aos Estados Unidos, mais especificamente em Nova Iorque, em 1949, Jonas Mekas, com um empréstimo, compra sua primeira câmera 16mm, uma Bolex, com a qual logo engrossa o time do cinema de vanguarda norte-americano. Cinema este que colocava em xeque o status da imagem, em oposição à uma tradição clássica baseada na proposição da arte como mímese (o que nem sempre vai significar, ou resultar, necessariamente, em um antirealismo, mas seu questionamento mesmo, ou reproposição através da quebra de suas hierarquias). "Nos filmes de vanguarda as imagens, em constelações, multiplicam-se. Não os fatos, não a representação naturalista de uma cadeia de acontecimentos. A poesia feita de imagens solicita um novo tipo de olhar (que é um olhar para dentro de si) e é necessário suspender o tempo"(XAVIER, 2005, p. 119).

De maneira geral, o trabalho das várias vertentes da vanguarda cinematográfica além da norte-americana - dar-se-á, pois, essencialmente, a partir do material fílmico, do que lhe é específico, via montagem, liberando-se das convenções próprias a uma forma particular de representação, características do projeto realista do século XIX (XAVIER, 2005, p. 99).

Sendo produzidos em plena capital do império da decupagem clássica e do cinema narrativo-representativo, os filmes da vanguarda americana constituem uma radical destruição do espaço-tempo contínuo, da imagem que ajuda o espectador a perceber os "fatos", do espetáculo claro e dotado de fotografias nítidas que abrem para um espaço ficcional auto-suficiente. Em suas várias tendências, o cinema poético 
representa sempre a introdução de fatores que perturbam a fruição de uma imagem transparente (...) Nas combinações de fotogramas isolados ou nas operações de montagem, superposição e desnaturalização da imagem, diferentes direções são seguidas, dentro de uma inclinação geral para a expressão da subjetividade do cineasta (XAVIER, 2005, p. 120).

Para Jonas Mekas, este cinema, como arte, atinge seus níveis mais altos "em direção a uma iluminação estética mais sutil e menos racional". E, neste movimento, equipara-se às outras artes em suas tendências mais modernas. Se lhe dissermos que há muita abstração no encaminhamento desta forma particular de negar o projeto ilusionista, Mekas nos responde negativamente. Num desvio empirista para um homem devotado ao cinema visionário e poético - ou melhor, numa demonstração do quanto há de comum entre empirismo e poesia visionária - ele assume que nada é mais concreto do que a presença imediata do objeto e as sensações dele derivadas: "O cinema, mesmo aquele mais ideal e mais abstrato, permanece em sua essência concreto; permanece a arte do movimento, luz e cor. Quando deixamos os preconceitos e os pré-condicionamentos de lado, nos abrimos para a concretude da experiência puramente visual e cinestésica, para o 'realismo' da luz e do movimento, para a pura experiência do olho, para a matéria do cinema. Assim como o pintor teve que se tornar consciente da matéria da pintura - a tinta; ou o escultor, igualmente, da pedra, madeira ou mármore; assim também, para chegar a sua maturidade, a arte do cinema teve que assumir a consciência de sua matéria - luz, movimento, celulóide, tela (Mekas, Movie journal, p. 219)” (MEKAS apud XAVIER, 2005, p. 107).

No trabalho de Jonas Mekas, que parece reivindicar o cinema em sua forma mais primitiva, no que diz respeito ao material, em busca da poesia, a manipulação deste material fílmico não chega a se constituir em sua radicalidade absoluta, como, digamos, na linha do que Ismail Xavier vai definir (de uma maneira arriscadamente reducionista) como prevalência do pedaço de celuloide sobre a ideia de imagem representativa - ou na inversão da definição mesma do que seja cinema levada aos extremos por Peter Kubelka ${ }^{5}$-, mas surge como uma implicação - linguagem/estética - de um cinema que se faz "sem planos" (seja o plano como ideia pré-concebida, seja o plano como decupagem), sem script, a partir da contingência. Daí, por exemplo, a importância da especificidade da película, que terá, também, desdobramentos na percepção temporal - a capacidade de leitura da câmera frame por frame, a "manipulação" do single frame, sua (des)aceleração, que possibilitava, digamos, um maior controle da imagem no momento, no ato de filmagem, o jogo com abstração e com as cores ${ }^{6}$ (além de uma

\footnotetext{
5 “O cinema não é movimento. O cinema é a projeção de fotos (stills) - ou seja, imagens que não se movem num ritmo acelerado (Kubelka, entrevista a Jonas Mekas, in New forms in films, p. 80)" (Apud XAVIER, Ismail. O discurso cinematográfico - a opacidade e a transparência. São Paulo: Paz e Terra, 2005. p. 107).

6 "There is this single frame I could concentrated on, could be very abstract like recording, playing with single frames, reading colors, you see a lot of that in Walden ... with video you can not, you can do that later in editing but during the taping you can have some control but it's limited (informação verbal)" ([com a película] existe esse único frame que eu poderia concentrar-me, poderia ser muito abstrato gravando, jogando com frames únicos, cores, você pode ver muito disso em Walden [filme de 1969], com o vídeo você pode fazer isso mais tarde, na edição, durante a filmagem você pode ter algum controle, porém ele é limitado). (Entrevista com Jonas Mekas. Disponível em: <https://www.youtube.com/watch?v=JtIQCxypAFM>. Acesso em: 28 Agosto 2014. Tradução nossa). O que não significa que Mekas será saudosista quanto à película e resistente quanto ao uso da tecnologia digital; na mesma entrevista, é enfático ao declarar que a troca da película pela atual tecnologia foi responsável por abrir-lhe muitos caminhos, novas perspectivas, além da possibilidade de transitar por qualquer
}

Anu. Lit., Florianópolis, v. 20, n. 2, p. 55-66, 2015. ISSNe 2175-7917 
montagem resultante de um trabalho propriamente manual, artesanal, realizado em um cortar e colar da película na moviola).

A técnica composicional não mudou, é ainda a montagem, mas agora a montagem passa para primeiro plano, e mostra-se enquanto tal. É por isto que se pode considerar que o cinema entra numa zona de indiferença em que todos os gêneros tendem a coincidir; o documentário e a narração, a realidade e a ficção ${ }^{7}$.

Em Walden (1969) - onde Mekas filma instantes, lampejos da cena avant-garde nova-iorquina nos anos 1960 e realiza, assim, um diário -, a primeira aparição em público da banda The Velvet Underground é marcada por uma aceleração desenfreada de frames, em uma dança - "quando o salto é festivo, é uma dança” (DIDI-HUBERMAN, 2009, p. 426, tradução nossa) - que une em um contínuo - caracterizado pela dessincronia imagem/som momentos de uma festa, o show de rock com a presença de Andy Warhol, duas crianças brincando (que são apresentadas por uma cartela como Alexandra e Jordan), e imagens da cidade de Nova Iorque, prenunciando, em termos de montagem, o que viria a se constituir, contemporaneamente, como linguagem do videoclipe musical. Mas não é apenas a vida urbana, moderna, agitada do cenário artístico underground de uma metrópole que recebe esse tratamento, como foco de interesse deste cinema: em Pleasures of Montauk (26 de Maio de 1973), excerto de As I Was Moving Ahead Occasionally I Saw Brief Glimpses of Beauty, a música do Velvet é substituída por um som que ora é ruído de um vento que sopra ininterruptamente do litoral, ora é água que escorre em algum riacho ou mato, e a vivência cotidiana de uma natureza um tanto quanto idílica aparece aos nossos olhos por uma repetição acelerada de planos. É pela via da repetição que arte e vida se tocam neste cinema, repetição que, como uma impossibilidade de continuidade (o que se repete nunca volta igual) e um hiato constitutivo, permite reinventar.

\begin{abstract}
tal cinema, ao inverter as proposições de Hollywood, passa também a chamar a atenção para o artista atrás da câmera. Da espessura da película e sua concretude, a atenção do espectador passa a ser dirigida ostensivamente para o gesto do "homem com a câmera" $[. .$.$] o cineasta transforma o objeto (filme) em vestígio do seu gesto:$ a imagem não representa um mundo ficcional mas aponta para o gesto que nela deixou suas marcas, suas direções, intensidade, hesitações e estilo [...] É o seu olhar que interessa, e o seu esforço está voltado para o nosso reconhecimento de sua experiência de exploração com a câmera transformada em extensão do corpo (XAVIER, 2005, p. 120).
\end{abstract}

situação de forma mais discreta, e filmar durante o tempo desejado, sem a preocupação com o momento inevitável do corte resultante do fim do rolo da película. No entanto, Mekas aponta que o vídeo foi responsável por transformá-lo mais em um antropólogo do que, digamos, um experimentador de linguagem-estética.

AGAMBEN, Giorgio. $O$ cinema de Guy Debord. Disponível em: $\leq \mathrm{http}$ ://intermidias.blogspot.com.br/2007/07/o-cinema-de-guy-debord-de-giorgio.html>. Acesso em: 01 Setembro 2014.

Anu. Lit., Florianópolis, v. 20, n. 2, p. 55-66, 2015. ISSNe 2175-7917 
Com frequência, Mekas coloca-se em cena; seu gesto do "homem com a câmera", como define Ismail Xavier em uma referência direta, imedita, ao cinema de Dziga Vertov (mais especificamente seu filme homônimo de 1929) ${ }^{8}$, não apenas se dá em seu enquadramento de mundos, mas também em como esses mundos o envolvem, interferem em seu trajeto-vida, sejam as ruas de Marselha (onde Mekas aparece tomando um café e fazendo brincadeiras com gatos), a vida, amizades, os personagens de Andy Warhol (em meio às exposições do artista pop, está lá Mekas tomando sopa com, dentre outros, John Lenon e Yoko Ono), o mundo familiar (mulher, filhos, casamentos, batizado, a despedida do irmão), a natureza (o verão entre amigos em uma casa de praia em Montauk): em qualquer uma dessas circunstâncias, indistintamente e sem hierarquias, o cinema de Mekas sempre deixa a marca, o vestígio do encontro, em toda sua simplicidade e banalidade, o objeto diário, cotidiano tornase imagem - "Life was simple minded \& silly", diz uma das cartelas/letreiros das "cenas da vida de Andy Warhol”. Encontro este que ao projetar o privado no público, e o público no privado, o familiar no desconhecido, e o desconhecido no familiar, não representa um mundo ficcional, mas cria/inventa suas ficções a partir de uma constelação de pequenas memórias que não se acumulam no passado (mesmo que o cineasta decrete em legenda "It's all memories now"), mas emergem/irrompem o presente como lampejos (uma memória amnésica, por isso não total, e sim fragmentária - "I have never been able really to figure out where my life begins and where it ends", relembro trecho da narração de As I Was Moving Ahead Occasionally I Saw Brief Glimpses of Beauty apontada no início deste texto); pequenos fragmentos de memórias que não cabem em, não seguem qualquer ideia de ordem - causa e efeito -, sucessão, mas aparecem em sua pura intensidade, como o lugar do acontecimento pequenas eternidades que desejam libertar-se, como definiria Borges (2010, p. 9), "da intolerável opressão do sucessivo"".

Sua grande virtude é, antes de tudo, rítmica (...) um ritmo feito de surpresas e de recorrências, de saliências e de pregnâncias, de sobrevivências e revivências observáveis na relação de cada imagem com as demais. E tudo se nos apresenta

\footnotetext{
${ }^{8}$ Entretanto, podemos dizer que é um "homem com a câmera de um cinema moderno", da imagem-tempo, nos termos de Deleuze, e não do cinema clássico, da imagem movimento, caso de Vertov. Apesar da definição que há na legenda inicial de Um homem com a câmera ajustar-se a Mekas ("excerto de um diário de um operador de câmera"), sua advertência ("este cinema é um filme experimental em comunicação cinematográfica de eventos reais sem a ajuda de intertítulos, sem a ajuda de uma história, sem a ajuda do teatro; esse trabalho experimental busca a criação de uma verdadeira linguagem internacional do cinema baseada na absoluta separação da linguagem do teatro e da literatura"), que procura justificar a estruturação de uma linguagem específica ao cinema, pode vir a se constituir oposição mesma à experimentalidade de Mekas. Talvez permaneça, como herança de Vertov, um cinema que vai às ruas em busca de um cotidiano.

9 "Como pode não perceber que a eternidade, a que tantos poetas aspiram com amor, é um artifício esplêndido que nos liberta, nem que seja fugazmente, da intolerável opressão do sucessivo?” (BORGES, 2010, p. 9)
} 
visualmente, acima de todo esquema explicativo, de toda determinação histórica (DIDI-HUBERMAN, 2009, p. 421, tradução nossa) ${ }^{10}$.

Ritmo este que é resultado não apenas da montagem - cujo corte, como definiria Deleuze (2005, p. 240), já não é mais racional, ou seja, que marca o fim de uma sequência ou o início de outra, mas irracional, "que não pertence nem a uma nem a outra, e começa a valer por si mesmo" -, mas é também música (o frequente som de um acordeon que o cineasta toca), e ainda vestígio da presença da poesia no cinema de Mekas: ora como oralidade (sua voz em off, que pode aparecer como canção, narração, declamação, autoreflexão sobre imagens, quando busca definir, em uma insistente indefinição ou fracasso desejado, sua vida, suas memórias), ora como forma-escrita. Como esta última, versos (cuja escansão, muitas vezes, parece obedecer unicamente ao espaço dado pelo limite do frame - há qualquer hierarquia entre cinema e poesia?), aforismos, que aparecem em cartelas ao longo dos filmes, entre-imagens, ou sobrepostas, seja como (não) títulos de alguns trechos fílmicos que se dão como capítulos ("About a man/whose lip is/always/trembling from/pain and sorrow/experienced in/the past which/only he knows"11), seja como haicais ("your face/has always/been/upon me"12) que, assim como as imagens, irrompem em lampejos, como proposições simples, corriqueiras, em toda sua brevidade, em um esvaziamento, livre de todo sentido pleno, não como provocação, mas suspensão da linguagem (BARTHES, 2007, p. 95) - o objetivo desta escrita não é a constituição do discurso, mas a cena, como um haicai de Bashô: "Como é admirável / Aquele que não pensa: 'A Vida é efêmera' / Ao ver um relâmpago" (BASHÔ apud BARTHES, 2007, p. 95).

O efêmero, o breve, em um corpo cotidiano. "Montar a câmera sobre um corpo cotidiano" (DELEUZE, 2005, p. 227). Deleuze (2005) aponta que, no cinema experimental, há dois pólos que são (re)encontrados: o corpo cotidiano e o corpo experimental. No cinema experimental, o procedimento fílmico pode montar a câmera sobre o corpo cotidiano, ou este cinema do corpo pode montar uma cerimônia, assumir um aspecto iniciático e litúrgico. Deleuze (2005, p. 230), ao desdobrar, desenvolver a questão, conclui que não se pode falar desses pólos em perspectiva contrária - “o que conta é menos a diferença entre os pólos que a passagem de um a outro, a passagem insensível das atitudes ou posturas ao 'gestus".

\footnotetext{
${ }^{10}$ Didi-Huberman sobre o trabalho de montagem realizado por Aby Warburg em seu Atlas Mnemosyne.

11 "Sobre um homem/cujo lábio está/sempre tremendo de/dor e mágoa/experenciadas em/um passado que/apenas ele conhece". No curta-metragem Song of Avignon (1998) (Disponível em: $<$ https://www.youtube.com/watch?v=QIOiMoG74kE $>$. Acesso em: 25 novembro 2015. Tradução nossa).

12 "seu rosto/tem sempre/estado/sobre mim". Ibdem.
} 
Esta noção de gestus permeia o cinema de Jonas Mekas, no sentido que Deleuze desenvolve - a partir do surgimento em Brecht -, como

vínculo ou o enlace das atitudes entre si, a coordenação de umas com as outras, mas isso só na medida em que não depende de uma história prévia, de uma intriga preexistente ou de uma imagem-ação. Pelo contrário, o gestus é o desenvolvimento das atitudes nelas próprias, e, nessa qualidade, efetua uma teatralização direta dos corpos, frequentemente bem discreta, já que se faz independentemente de qualquer papel (DELEUZE, 2005, p. 231).

O café da manhã do próprio Mekas, em meio aos gatos, diante da câmera, assim como diante da câmera ele senta, cruza as pernas, e encara a lente fixamente; um homem, uma mulher que catam pedras na praia; as crianças que repetem exaustivamente suas brincadeiras, como a teatralização de uma luta, durante um certo verão; a menina bailarina que ensaia na sala de casa, diante de duas mulheres; a dança desenfreada do rock and roll, a proposição mesma da filmagem das cenas da vida de Andy Warhol ${ }^{13}$ :

I film what happens and I've never known what will happen. I don't live according to planes. I filmed a lot of Andy Warhol, through, you know, his working, doing nothing $[\ldots]$ he's not sitting in front of some television, some interviewers are asking questions... He is he is like playing with children, doing nothing, sitting on the ocean... something (informação verbal) ${ }^{14}$.

Do artista pop ao familiar (des)conhecido, as cenas da vida, as cenas de uma vida, as categorias desta vida, são constituídas das atitudes-posturas de um corpo que se constitui em trânsito entre uma experimentalidade e uma cotidianidade.

\section{Cinema-asilo}

Em 1944, Mekas (nascido na Lituânia) foi levado, junto ao seu irmão, pelos nazistas, a um campo de concentração em Elmshorn, na Alemanha. No final de 1949, pós-guerra, a organização $U N$ Refugee conduz os dois irmão a Nova Iorque, onde se estabelecem no Brooklyn (bairro onde Mekas vive até hoje). Logo depois de sua chegada, como já dito anteriormente, o incipiente cineasta compra sua primeira câmera. A partir daí, sua vida e o cinema fundem-se, em seus vários aspectos: em 1954, junto ao seu irmão, dá início à revista Film Culture, e, em 1958, à sua coluna Movie Journal no Village Voice; em 1962, ele funda a

13 Scenes from the life of Andy Warhol (1990), conta-nos Jonas Mekas em entrevista, foi "finalizado" sob encomenda, para uma retrospectiva de Andy Warhol no Centro Pompidou, em Paris. Mekas tinha as imagens de Warhol, feitas ao acaso, guardadas, e quando requisitado, montou-as (Informação verbal. Disponível em: $<$ https://www.youtube.com/watch?v=JtIQCxypAFM>. Acesso em: 28 agosto 2014).

14 "Eu filmo o que acontece e eu nunca sei o que vai acontecer. Eu não vivo de acordo com planos. Eu filmei muito do Andy Warhol, seu trabalho, ele fazendo nada [...] ele não está em uma emissora de televisão, com alguns entrevistadores fazendo-lhe perguntas... Ele está bricando com crianças, fazendo nada, sentado em frente ao oceano... qualquer coisa". (Entrevista com Jonas Mekas. Disponível em: $<$ https://www.youtube.com/watch?v=JtIQCxypAFM>. Acesso em: 28 agosto 2014. Tradução nossa).

Anu. Lit., Florianópolis, v. 20, n. 2, p. 55-66, 2015. ISSNe 2175-7917 
Film-Makers' Cooperative, e, em 1964, a Film-Makers' Cinematheque, que resultou na Anthology Film Archives, um dos maiores e mais importantes repositórios do cinema de vanguarda.

É o vestígio da viagem, do deslocamento (nomadismo), passagem, desenraizamento, desterro que marca o cinema de Jonas Mekas, o qual toma uma forma de perambulação; um cinema diário - ou cinema-diário (diaries, notes and sketches é o subtítulo de um de seus filmes, Walden ) -, que se faz no contato, este tanto como encontro quanto contaminação. O encontro com o outro, o encontro de corpos, a contaminação das formas (cinema e poesia, perfomance $\left.{ }^{15}\right)$. Um cinema que se faz vida, existência, e por isso mesmo exílio ${ }^{16}$.

I used to say that my country was culture. After I was throned out, tripped out from my own home I decided that I want to belong that any country and that my country is culture. As time went, the idea what is culture became confuse. I know we live in a civilization, I know that we are in a certain civilization but where culture is and what culture is I don't know anymore. So at that point I decided that maybe my country is cinema. Cinema is my five continents and I decided that I want to live in five continents at the same time. I will live in one small area like a small republic of that continent and that republic to me is poetry and I think what I feel is important and what is lacking in cinema is poetry so I support poetry as my flag. I carry a flag of poetry and poetry is my country ${ }^{17}$.

Jean-Luc Nancy (1996), em seu texto intitulado A existência exilada, coloca que Jean Améry, em seu livro sobre os campos de concentração, propõe, em um de seus capítulos, a seguinte questão: “Em que medida temos necessidade de uma Heimat [pátria]?” Questão esta que, continua Nancy, não poderia ser pensada antes da deportação, e que a própria deportação nos obriga a pensar: "não significa que seja necessária uma alegada propriedade 'natural', originária, identitária; significa que existe o próprio e que a desapropriação é violência" (NANCY, 1996, p. 38, tradução nossa).

\footnotetext{
${ }^{15}$ Aqui, especificamente, penso no excerto Salvador Dali at work - April 18, 1964, onde enquanto ouvimos uma narração-poemas de Mekas, sobre Salvador Dalí, vemos imagens de alguns happennings que resultam da interação mesma entre o cineasta e o artista (Disponível em: $<$ https://www.youtube.com/watch? $\mathrm{v}=\operatorname{Simm} 38 \mathrm{wZp60}>$. Acesso em: 23 outubro 2014).

16 A partir da proposição de Jean-Luc Nancy (1996) do exílio como constituição mesma da existência e, reciprocamente, a existência que seria a consistência do exílio.

17 "Eu costumava dizer que o meu país era a cultura. Depois que eu fui colocado para fora da minha própria casa eu decidi que eu queria pertencer a qualquer país e que meu país era cultura. Com o passar do tempo a ideia do que significava cultura tornou-se confusa. Eu sei que vivemos em uma civilização, eu sei que estamos em uma certa civilização mas onde a cultura está e o que cultura é eu não sei mais dizer. Então a partir daí eu decidi que talvez meu país pudesse ser o cinema. Cinema é os meus cinco continentes e eu decidi que eu queria viver nos cinco continentes ao mesmo tempo. Eu viverei em uma pequena área uma pequena república deste continente e essa república para mim é a poesia e eu penso que o que eu sinto é importante e o que está faltando no cinema é poesia. Assim eu carrego a poesia como minha bandeira e a poesia é o meu país" (Mekas no trecho intitulado Un portrait de Jonas Mekas, un cinéaste lituanien, uma das sequências do documentário Meanwhile a butterfly flies, de 2002. Disponível em: <https://www.youtube.com/watch?v=bihaVMiqwws >. Acesso em: 23 Outubro 2014. Tradução nossa).
}

Anu. Lit., Florianópolis, v. 20, n. 2, p. 55-66, 2015. ISSNe 2175-7917 
Se o próprio é exílio, sua dimensão de propriedade poderia denominar-se talvez "asilo". O campo de concentração é o contrário do asilo. O campo é o exílio como desapropriação. $\mathrm{O}$ asilo, por sua vez, é o exílio como próprio: o asilo da hospitalidade, por exemplo, do qual falava Cacciari. O asilo é o lugar de quem não pode ser aprisionado (é o sentido do grego ásylos: aquele que não pode ser convertido em presa, em despojos). Pensar o exílio como asilo - e não como campo de deportação -, é justamente pensar o exílio como constituindo por si mesmo a propriedade do próprio: em seu exílio, está abrigado, não pode ser expropriado de seu exílio.

Esse lugar de asilo no exílio é triplo: lugar do corpo, lugar da linguagem, lugar do "com" (NANCY, 1996, p. 38, tradução nossa).

Seu cinema, que Mekas pensa e se coloca a partir da ideia/escolha de não ter pátria, ou de pertencer a todas as elas, simultaneamente, talvez possa ser pensado mesmo nesta chave do exílio como asilo. Um cinema em exílio, cinema-asilo, que não prepara um regresso ou aponta um lugar determinado de chegada, mas sustenta a passagem, um movimento iniciado e sem prazo para término - ao mesmo tempo, sobrevivência e suspensão de uma memória, abrigo do corpo, da linguagem, do encontro, onde parece sempre se desenhar a possibilidade, abertura para a invenção de um espaço novo, inédito, espaço-vida, espaço-arte, sem fronteiras.

\section{AGRADECIMENTOS}

Prof. Dr. Jair Tadeu da Fonseca (UFSC)

\section{Referências}

AGAMBEN, Giorgio. $O$ cinema de Guy Debord. Disponível em: $\leq$ http://intermidias.blogspot.com.br/2007/07/o-cinema-de-guy-debord-de-giorgio.html $>$. Acesso em: 01 Setembro 2014.

BARTHES, Roland. O império dos signos. Tradução de Leyla Perrone-Moisés. São Paulo: WMF Martins Fontes, 2007.

BORGES, Jorge Luis. História da Eternidade. São Paulo: Companhia das Letras, 2010.

DELEUZE, Gilles. A imagem-tempo: cinema II. Tradução de Eloisa de Araujo Ribeiro. São Paulo: Editora Brasiliense, 2005.

; GUATTARI, Félix. Mil Platôs: capitalismo e esquizofrenia, vol. 4. Tradução de Suely Rolnik. São Paulo: Ed. 34, 1997.

DIDI-HUBERMAN, Georges. La imagen superviviente - Historia del arte y tiempo de los fantasmas según Aby Warburg. Madri: Abada Editores, 2009.

. Sobrevivência dos vaga-lumes. Tradução de Vera Casa Nova Márcia Arbex. Belo Horizonte: Editora UFMG, 2011.

MORÃO, Maria Dora; LABAKI, Amir (Orgs.). O cinema do real. São Paulo: Cosac Naify, 2005.

NANCY, Jean-Luc. La existência exilada. Archípelago 26-27, Barcelona, inverno 1996. 
XAVIER, Ismail. O discurso cinematográfico - a opacidade e a transparência. São Paulo: Paz e Terra, 2005.

[Recebido em abril de 2015 e aceito para publicação em junho de 2015]

\section{Jonas Mekas - cinema glimpses}

Abstract: This article reflects on the cinematic creation of Jonas Mekas, one of the filmmakers and thinkers of American avant-garde cinema, as such, brings in his films, trace of new propositions of language/composition, another comprehension of time and its passage, by the abandonment of any chronology and narrative linearity. From this argument, unfolds reading a cinema that is made in and by the displacement, transit through everyday, openness to chance, contingency; not part of a space-time unit but fragments - which fragment itself as ethical possibility in the face of otherness; passages, traces, traces of a gesture. Designing the intimate scenes in public in a kind of continuous and unpretentious celebration of everyday life, the family. Cinema in exile, cinema-asylum - at the same time, survival and suspension of memory, body and language shelter, place of the meeting, which always seems to draw the possibility, opening for the invention of a new space, inedited, space- life, space-art without borders.

Keywords: Cinema. Everyday. Fragment. Transit. Asylum.

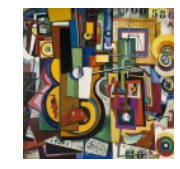

